\title{
Role of Growth Hormone in the Regulation of Insulin Sensitivity and Lipid Metabolism in Patients with Non Insulin Dependent Diabetes Mellitus
}

\author{
TAKASHI IIZUKA, YoshihiKo KURAMOTO, Masao OMURA, AND TETSUO NISHIKAWA
}

Department of Medicine, Yokohama Rosai Hospital, Kanagawa 222, Japan

IT IS KNOWN that impaired insulin sensitivity plays a crucial role in the regulation of glucose metabolism in non-insulin dependent diabetes mellitus (NIDDM) and seems to be closely related to the development of diabetic complications such as sclerotic changes in arteries. On the other hand, insulin and insulin-antagonizing hormones including $\mathrm{GH}$ are known to regulate glucose metabolism and insulin sensitivity $[1,2]$. We therefore attempted to investigate the effect of $\mathrm{GH}$ on insulin sensitivity in patients with NIDDM in order to clarify the role of $\mathrm{GH}$ in the regulation of insulin sensitivity.

\section{Materials and Methods}

One-hundred fourty three diabetic patients and twenty nine non-diabetic controls whose age, body mass index (BMI) and sex were almost the same as those of diabetic patients were subjected to those studies. Clinical profiles of the subjects, all of whom were men, are summarized in Table 1 . Fifty-five diabetic patients were treated with insulin, 23 were treated with oral hypoglycemic agents, and the remaining 35 patients were treated with a restricted diet alone.

Euglycemic glucose clamping was performed in each subject with an artifificial pancreas apparatus STG-22 (Nikkiso, Tokyo, Japan), according to the

Correspondence to: Dr. Tetsuo NISHIKAWA, Department of Medicine, Yokohama Rosai Hospital, 3211 Kozukue-cho, Kohoku-ku, Yokohama City, Kanagawa 222, Japan

Key words: Non-insulin dependent diabetes mellitus, GH, Lipid metabolism, Insulin sensitivity, Euglycemic glucose clamping method of Zuniga-Guajardo, et al. [3]. After an overnight fast, an indwelling catheter was inserted into an antecubital vein for glucose and insulin administration. A second catheter was placed in a retrograde fashion into a superficial hand vein in the opposite arm for blood sampling. The hand was kept in a warming chamber at $69^{\circ} \mathrm{C}$ to ensure arterization for venous blood [4]. The infusion of insulin (Novolin R, Novo-Nordisk A/S, Denmark) was started and maintained at a rate of $4.48 \mathrm{mU} /$ $\mathrm{kg}$ body weight/min, and then various amounts of $20 \%$ dextrose were infused for $90 \mathrm{~min}$ to achieve a steady level of plasma glucose as $100 \mathrm{mg} / \mathrm{d} l$. The glucose metabolized (M) during the final 20 min of the glucose clamping was calculated on the basis of the amount of glucose infused and expressed in terms of $\mathrm{mg} / \mathrm{kg}$ body weight $/ \mathrm{min}$. Under these steady-state conditions of constant euglycemia, all the glucose infused is taken up by the cells and thus serves as a measure of the

Table 1. Clinical characteristics in diabetics (DM) and age-, BMI-matched controls

\begin{tabular}{lcc}
\hline & Control & DM \\
\hline Number & 29 & 143 \\
Age $(\mathrm{yr})$ & $43.0 \pm 16.1$ & $44.3 \pm 10.0$ \\
Height $(\mathrm{cm})$ & $166.8 \pm 7.5$ & $168.3 \pm 6.4$ \\
Body-weight $(\mathrm{kg})$ & $67.6 \pm 18.8$ & $66.1 \pm 14.4$ \\
BMI $\left(\mathrm{kg} / \mathrm{m}^{2}\right)$ & $24.2 \pm 6.4$ & $23.3 \pm 4.4$ \\
HbA1c $(\%)$ & $4.8 \pm 0.4$ & $9.4 \pm 2.9^{* * *}$ \\
FBG $(\mathrm{mg} / \mathrm{d} l)$ & $99.9 \pm 25.7$ & $203.3 \pm 162.1^{* * *}$ \\
Duration $(\mathrm{yr})$ & & $4.2 \pm 4.9$ \\
Therapy & & \\
Diet alone & & $35(24 \%)$ \\
Sulfonylurea & & $23(16 \%)$ \\
Insulin & & $55(60 \%)$ \\
\hline
\end{tabular}

Mean \pm SD. ${ }^{* * * P}<0.001$ : vs. control. 
amount of glucose metabolized by the entire body in response to the infused insulin. The validity of these measurements is based on the assumption that endogenous glucose production has been entirely suppressed [5]. A venous blood sample was taken in the morning after $12 \mathrm{~h}$ of fasting, and the plasma glucose level was assayed by the glucose oxidase method. Blood samples were analyzed in a Nippon Denshi autoanalyzer (JCA RX20, Tokyo, Japan) for plasma glucose and serum levels of cholesterol and triglyceride. HDL-cholesterol was measured by heparin-mangenese methods. The LDL-cholesterol was calculated with the following formula:

LDL-cholesterol $=($ total cholesterol $)-($ HDL-cholesterol)-(triglyceride/5). The serum hormone level including $\mathrm{GH}$ was estimated by means of its specific radioimmunoassay kit which is commercially available.

Data are given as the mean $\pm \mathrm{SD}$. Continuous variables were compared by unpaired Student's $t$ test. Pearson's correlation coefficient test was performed by means of a computerized program (StatView 4.0, Macintosh, Apple, Cupertino, CA). Results were considered as statistically significant at $P<0.05$.

\section{Results}

\section{Basal GH value and M value}

Basal levels of $\mathrm{GH}$ in 143 diabetic subjects were significantly lower than those of 29 controls (2.36 \pm 3.03 vs. $4.10 \pm 5.17 \mathrm{ng} / \mathrm{ml}, P<0.01)$. M values during euglycemic glucose clamping in 143 diabetics were also significantly lower than those in 29 controls $(6.72 \pm 2.42$ vs. $7.40 \pm 2.35 \mathrm{mg} / \mathrm{kg} / \mathrm{min}$, $P<0.05)$. As shown in Fig. 1, a significantly positive correlation was observed between the basal GH value and $M$ value during euglycemic glucose clamp in diabetics $(\mathrm{r}=0.18, P<0.05)$ and in also controls $(\mathrm{r}=0.38, P<0.05)$.

\section{Serum concentrations of lipids}

There was no significant difference between the diabetics and the controls in serum levels of triglyceride, HDL-cholesterol and non-esterified fatty acids (NEFA), but the serum concentrations of total cholesterol and LDL cholesterol were
(A)

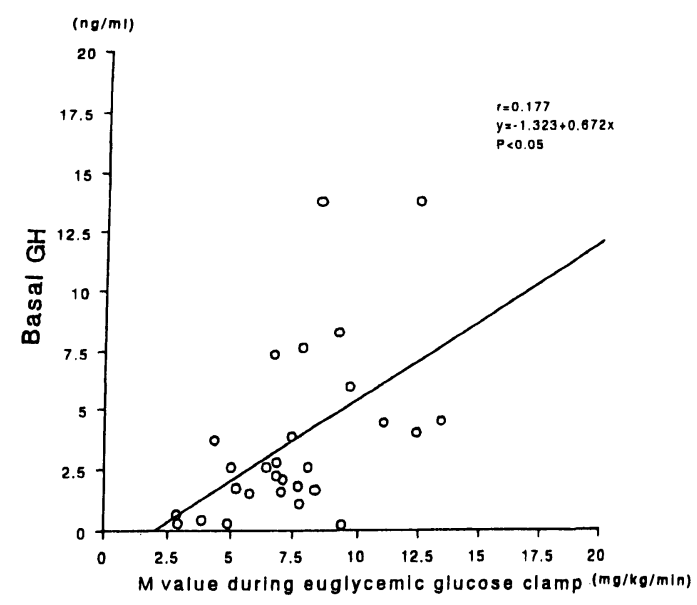

(B)

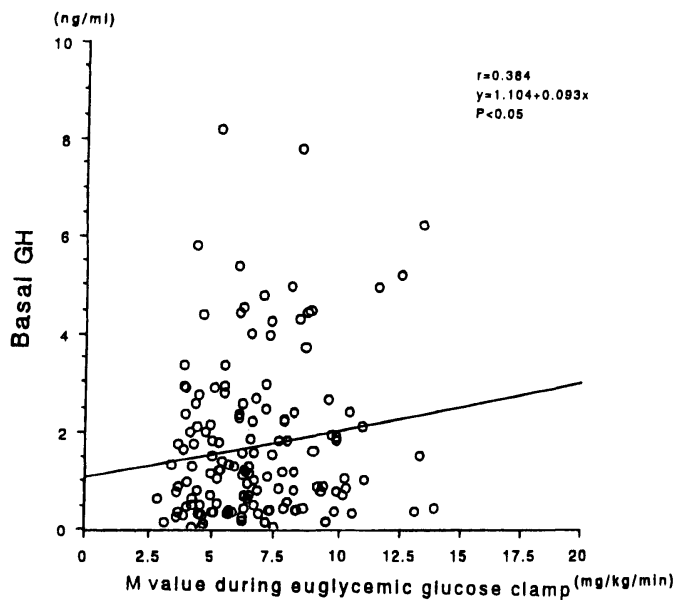

Fig. 1. Relationship between basal GH level and the $M$ value in controls (A), and diabetic patients (B). A significant correlation was found in each group $(\mathrm{r}=0.177, P<0.05 ; \mathrm{r}=0.384, P<0.05)$.

significantly higher in diabetics than in controls (total cholesterol: $193 \pm 39$ vs. $168 \pm 42 \mathrm{mg} / \mathrm{dl}$, $P<0.05$, LDL-cholesterol: $127 \pm 38$ vs. $108 \pm 35 \mathrm{mg} /$ $\mathrm{d} l, P<0.05)$. Serum apolipoprotein A-I, A-II, C-2, $C-3$ and $E$ values were not different between the diabetics and the controls, whereas apolipoprotein $\mathrm{B}$ values and the ratio of apolipoprotein C3 to C2 were significantly higher in the diabetics than in the controls $(95 \pm 25$ vs. $77 \pm 26 \mathrm{mg} / \mathrm{dl}, P<0.05,2.25$ \pm 0.88 vs. $1.71 \pm 0.54, P<0.05)$.

\section{Discussion}

The present study showed that the basal GH values were significantly lower in the diabetics than 
Table 2. Laboratory findings in diabetics (DM) $(n=143)$ and age-, BMI-matched controls $(\mathrm{n}=29)$

\begin{tabular}{|c|c|c|c|}
\hline & & Control & DM \\
\hline Number & & 29 & 143 \\
\hline M value & $(\mathrm{mg} / \mathrm{kg} / \mathrm{min})$ & $7.40 \pm 2.35$ & $6.72 \pm 2.42^{*}$ \\
\hline Basal GH & $(\mathrm{ng} / \mathrm{ml})$ & $4.10 \pm 5.17$ & $2.36 \pm 3.03^{* *}$ \\
\hline T-chol & $(\mathrm{mg} / \mathrm{d} l)$ & $168.1 \pm 42.0$ & $193.1 \pm 39.4^{*}$ \\
\hline TG & $(\mathrm{mg} / \mathrm{d} l)$ & $100.0 \pm 51.8$ & $105.4 \pm 54.2$ \\
\hline LDL-chol & $(\mathrm{mg} / \mathrm{d} l)$ & $107.9 \pm 35.1$ & $127.1 \pm 37.8^{*}$ \\
\hline HDL-chol & $(\mathrm{mg} / \mathrm{d} l)$ & $40.4 \pm 8.5$ & $44.4 \pm 15.8$ \\
\hline NEFA & $(\mathrm{mEq} / \mathrm{l})$ & $1.23 \pm 0.51$ & $1.14 \pm 0.48$ \\
\hline Apo.A1 & $(\mathrm{mg} / \mathrm{d} l)$ & $104.8 \pm 19.2$ & $111.8 \pm 24.9$ \\
\hline A2 & $(\mathrm{mg} / \mathrm{d} l)$ & $24.8 \pm 6.3$ & $26.1 \pm 6.4$ \\
\hline $\mathrm{B}$ & $(\mathrm{mg} / \mathrm{d} l)$ & $77.2 \pm 25.5$ & $94.7 \pm 25.4^{*}$ \\
\hline $\mathrm{C} 2$ & $(\mathrm{mg} / \mathrm{d} l)$ & $3.2 \pm 1.8$ & $4.7 \pm 2.3$ \\
\hline $\mathrm{C} 3$ & $(\mathrm{mg} / \mathrm{d} l)$ & $6.7 \pm 4.0$ & $7.6 \pm 3.8$ \\
\hline $\mathrm{E}$ & $(\mathrm{mg} / \mathrm{d} l)$ & $4.6 \pm 1.2$ & $4.9 \pm 1.5$ \\
\hline IRI & $(\mathrm{uU} / \mathrm{ml})$ & $6.4 \pm 4.3$ & $7.6 \pm 10.4$ \\
\hline \multicolumn{2}{|c|}{ Apo.C3/C2 ratio } & $1.71 \pm 0.54$ & $2.25 \pm 0.88^{*}$ \\
\hline
\end{tabular}

Mean \pm SD. ${ }^{*} P<0.05$ : vs. control, ${ }^{* *} P<0.01$ : vs. control.

in the controls whose age, sex and BMI were matched, and serum levels of total cholesterol and LDL-cholesterol were significantly higher in the diabetics than in the controls. It has already been reported that $\mathrm{GH}$ plays an important role in the regulating the metabolism of lipids including lipoproteins as well as in the regulation of carbohydrate and protein metabolism [6]. Recent studies have demonstrated that blood levels of total cholesterol [7], LDL-cholesterol $[8,9]$, apolipoprotein B $[8,9]$ and triglyceride $[7,9]$ increased, and HDL-cholesterol were decreased $[8,10]$ in adult patients with GH deficiency (GHD). It is therefore suggested that cases with a low GH level seem to possess abnormal lipid metabolism such as hyperlipidemia, and also that $\mathrm{GH}$ may play a crucial role in the regulation of lipid metabolism. It is known that replacement of GH in GHD adults alters the body composition and energy metabolism through its lipolytic, protein anabolic, and antinatriuretic actions $[7,11]$. It is therefore speculated that diabetic patients with a low basal level of GH may have an impairment in lipid metabolism and body composition, possibly resulting in the development of atherosclerotic changes. It is known that acromegalics with a high level of $\mathrm{GH}$ are usually suffering from diabetes mellitus, suggesting that excess amounts of GH clearly induce abnormal glucose metabolism with diabetic changes. Further investigations are needed in order to clarify exactly the role of GH in the pathophysiology of NIDDM.

This study also demonstrated a positive correlation between the basal GH level and the $M$ value which reflects insulin sensitivity in peripheral tissues in all patients with diabetics and controls. There has been no report describing in detail the correlation between insulin sensitivity and basal $\mathrm{GH}$ value in diabetics. It is therefore suggested that GH may be one of the factors regulating insulin sensitivity in patients with NIDDM as well as in controls. Fowelin et al. [12] reported that insulin sensitivity was significantly suppressed in patients with adult GHD by GH treatment for 6 weeks, and after 26 weeks of GH treatment, insulin sensitivity was apparently improved to the basal level before the use of $\mathrm{GH}$. It is therefore difficult to determine the exact effect of $\mathrm{GH}$ administration on insulin sensitivity and the role of GH in the regulation of insulin sensitivity, while our present data showed that diabetics and controls with low serum concentrations of $\mathrm{GH}$ had impaired insulin sensitivity. It is therefore suggested that GH may directly or indirectly regulate insulin sensitivity.

\section{References}

1. Campbell P, Bolli G, Cryer P, Gerich J (1985) Pathogenesis of the dawn phenomenon in patients with insulin-dependent diabetes mellitus. Accelerated glucose production and impaired glucose utilization due to nocturnal surges in growth hormone secretion. N Engl J Med 312: 1473-1479.

2. Perriello G, de Feo P, Torlone E, Fanelli C, Santeusanio F, Brunetti P, Bolli GB (1990) Nocturnal spikes of growth hormone secretion cause the dawn phenomenon in Type 1 (insulin-dependent) diabetes mellitus by decreasing hepatic (and extrahepatic) sensitivity to insulin in absence of insulin waning. Diabetologia 33: 52-59.

3. Zuniga-Guajardo S, Jimenez J, Augel A, Zinman B (1986) Effect of massive obesity on insulin sensitivity and insulin clearance and the metabolic response to insulin as assessed by the euglycemic clamp technique. Metabolism 35: 278-282.

4. McGuire EAH, Helderman JH, Tobin JD, Andres $R$, Berman M (1976) Effects of arterial versus venous 
sampling on analysis of glucose kinetics in man. J Appl Physiol 41: 565-573.

5. Rizza RA, Mandarino LJ, Gerich JE (1981) Doseresponse characteristics for effects of insulin on production and utilization of glucose in man. $A m J$ Physiol 240: E630-E639.

6. Angelin B, Rudling M (1994) Growth hormone and hepatic lipoprotein metabolism. Curr Opin Lipidol 5: 160-165.

7. Salomon F, Cuneo RC, Hesp R, Sonksen PH (1989) The effects of treatment with recombinant human growth hormone on body composition and metabolism in adults with growth hormone deficiency. $N$ Eng J Med 321: 1797-1803.

8. Cuneo RC, Salmon F, Watts GF, Hesp R, Sönksen PH (1993) Growth hormone treatment improves serum lipids and lipoproteins in adults with growth hormone deficiency. Metabolism 42: 1519-1523.
9. De Boer H, Blok GJ, Voerman HJ, Phillips M, Schouten JA (1994) Serum lipid levels in growth hormone-deficienct men. Metabolism 43: 199-203.

10. Rosen T, Eden S, Larsson G, Wilhelmsen L, Bengtsson B-A (1993) Cardiovascular risk factors in adult patients with growth hormone deficincy. Acta Endocrinol 129: 195-200.

11. Bengtsson B-A, Eden S, Lonn L, Krist H, Stokland A, Lindstedt G, Bosaeus I, Tolli J, Sjostrom L, Isaksson OG (1993) Treatment of adults with growth hormone (GH) deficiency with recombinant human GH. J Clin Endocrinol Metab 76: 309-317.

12. Fowelin J, Attvall S, Lager I, Bengtsson B-A (1993) Effects of treatment with recombinant human growth hormone on insulin sensitivity and glucose metabolism in adults with growth hormone deficiency. Metabolism 42: 1443-1447. 